\title{
The Architecture of an Information System for Public Relations via Mobile Application Using In-depth User Experience for Proactive Perception of Information
}

\author{
Sengdavnah Jularlark ${ }^{1}$, Pinanta Chatwattana ${ }^{1} \&$ Pallop Piriyasurawong ${ }^{1}$ \\ ${ }^{1}$ King Mongkut's University of Technology North Bangkok, KMUTNB, Bangkok, Thailand \\ Correspondence: Sengdavnah Jularlark, King Mongkut's University of Technology North Bangkok, 1518 \\ Pracharat 1 Road Wong Sawang, Bang Sue, Bangkok 10800, Thailand. E-mail: aeung1992@gmail.com
}

Received: July 16, 2021

Accepted: August 21, $2021 \quad$ Online Published: August 30, 2021

doi:10.5539/jel.v10n5p91

URL: https://doi.org/10.5539/jel.v10n5p91

\begin{abstract}
The objectives of this research were as follows: 1) To study, analyze, synthesize documents and researches related to the architecture of an information system for public relations via mobile application using in-depth user experience for proactive perception of information, 2) Design the architecture of an information system for public relations via mobile application using in-depth user experience for proactive perception of information, 3) Develop the architecture of an information system for public relations via mobile application using in-depth user experience for proactive perception of information, and 4) Study the results of evaluating the suitability of the architecture of an information system for public relations via mobile application using in-depth user experience for proactive perception of information. The samples used in the research were 20 experts in information system development from various institutions in higher education. The assessment results found the following: 1) The developed system architecture has four components: stakeholders, user experience process, output and feedback, 2) The results of the evaluation of the suitability of the developed system architecture found that (2.1) the assessment results of the suitability of the developed system architecture (aspect of integrated components) was appropriated at a high level (Mean=4.43, S.D. $=0.67)(2.2)$ the assessment results of the suitability of the developed system architecture (issue by separated components) were appropriated at a high level (Mean=4.37, S.D. $=0.80$ ), and 3) The assessment results of the suitability in implementing the developed system architecture were appropriated at a high level (Mean=4.17, S.D. $=0.74$ ), respectively.
\end{abstract}

Keywords: information system, mobile application, in-depth user experience, proactive perception of information

\section{Introduction}

In the present technology era, many applications are emerging. Plenty of businesses build applications to serve their customers to make it more convenient to use (Mongkol, 2017). In-depth user experience is a way to draw perspectives and feelings from the user experience in the interaction point. To create a conceptual framework for the development and design of the service model. It can provide an overview of the factors that influence the user experience of the service. These factors have been compiled from the perspective of real users (Phiraphon, 2018). This method allows seeing the relationship of the entire service system. Then increasing user experience satisfaction (Jawdat, Obeidat, \& Aljanaby, 2011). In addition, user experience design. Nowadays, social media and mobile applications are viral, whether in business or organizations (Waraporn, 2019). Whether education, applications to communicate with students and staff, such as WhatsApp, Line, Messenger, and other applications (Satmunee \& Boriruk, 2019), make communication faster and more convenient.

An information system is a storage system, data processing by relying on people and information technology to obtain information appropriate for each task or duty (Fichten et al., 2013). Information systems, including hardware, software, network system, database, system developers, system users, related employees, and experts in all disciplines. All the elements work together to prescribe, collect data, store data and data processing to create information and deliver the results obtained to support the work, decision making, planning and administration of the organization (Saenkham, Jeewattana, \& Pimklat, 2019). A good information system must come from appropriate data. The storage of data and information must be well controlled. For example, personnel have the right to use the information (Chatwattana \& Piriyasurawong, 2015). Confidential information 
must be handled the right to access securely. Besides, the stored data must not be lost or destroyed accidentally (Jirasatjanukul, Nilsook, \& Wannapiroon, 2019). Information scoping requires information resources that include modern technologies with the previous knowledge to integrate into a new information system. That can be used according to the objectives, such as information systems for working in various business organizations. Also, information systems that support communication and support education can define work effectively (Fichten et al., 2013).

Mobile application is developing applications for mobile devices such as mobile phones and tablets that support the usage. That makes phone users more convenient and easy to use (Sombut \& Manon, 2016). Mobile phones or smartphones have various operating systems, and the popular operating systems are iOS and Android. It has resulted in the development of smartphone applications such as maps, games, and chat programs. Besides, applications that support various businesses and applications that support educational services (Yilmaz, 2016).

The in-depth user experience is a design that combines in-depth interviews and the user experience process (UX Process) to bring various needs of users from in-depth interviews to design an efficient and appropriate system. The user experience design brings out different feelings from users, such as needs, motivation, user sense, and suitable technology with various information for effective design (Jawdat, Obeidat, \& Aljanaby, 2011). The user experience process is not only a system design that is easy to use but also that the system designer must take that workpiece to meet both the business and overall needs - besides, the application of technology that users can use effectively (Rodsoodthi, 2018). The technology can also suit the potential of product development, integrated with the system design that perfectly matches the target users. An in-depth interview is a question and discussion between the interviewer and the interviewee: a thorough, in-depth inquiry and a way to gather information without using a questionnaire, whereas using an open-ended question to get the details and valuable information to the researchers. It requires the interviewer to find the contents that need to be studied intimately (Rita, 1999).

The study of the above documents shows that information and communication technology is critical to students' daily lives, especially in communication in the 21 st century (Rodsoodthi, 2018). Including smartphones, tablets, and computers is an essential factor in communication via online social media. Therefore, the researcher has proposed an idea to develop an information system architecture for public relations in the form of an application to use as the guidelines for developing information systems that can work on smartphones and tablets to become a tool to support the distribution of reliable information.

\section{Research Objectives and Hypothesis}

\subsection{Research Objectives}

1) To study, analyze, synthesize the documents and researches related to the architecture of an information system for public relations via a mobile application using in-depth user experience for the proactive perception of information.

2) To design the architecture of an information system for public relations via a mobile application using in-depth user experience for the proactive perception of information.

3) To develop the architecture of an information system for public relations via a mobile application using in-depth user experience for the proactive perception of information.

4) To study results of assessing the suitability of the development of the architecture of an information system for public relations via a mobile application using in-depth user experience for the proactive perception of information.

\subsection{Research Hypothesis}

Assessment of the suitability by the experts for the development of the architecture of an information system for public relations via a mobile application using in-depth user experience for the proactive perception of information is at a high level.

\section{Methodology}

The research is to design and develop the architecture of an information system for public relations via a mobile application using in-depth user experience for the proactive perception of information. There are four steps in the research methodology according to the research objectives as follows:

Step 1: Study, analyze, synthesize documents and researches related to the architecture of an information system for public relations via a mobile application using in-depth user experience for the proactive perception of information. The researcher conducted a study of an analytical, and synthesis from documents and researches, including information systems (Tivawong, 2012), mobile applications (Karapakdee \& Chatwattana, 2016), 
in-depth user experiences (Ngewtong, 2017; Rodsoodthi, 2018), and the proactive perception of information (Chiemwichitra, 2015) as a guideline for defining a conceptual framework for developing system architecture.

Step 2: Design the architecture of an information system for public relations via a mobile application using in-depth user experience for the proactive perception of information. The researcher designed the developed system architecture using the use case diagram, context diagram, and swim lane diagram.

Step 3: Develop the architecture of an information system for public relations via a mobile application using in-depth user experience for the proactive perception of information. In this section, the researcher applied the concept of user experience design (UXD) theory as a process for designing and developing a proposed system architecture consisting of 5 steps: behaviour of user research, analysis, design, build a prototype, and user testing of the prototype.

Step 4: Study results of assessing the suitability of developing architecture of an information system for public relations via a mobile application using in-depth user experience for the proactive perception of information. Then conduct a feasibility study to develop the architecture of an information system for public relations via a mobile application using in-depth user experience for the proactive perception of information. By 20 experts in information system development from various institutions in higher education. The instrument used is the suitability assessment form for developing the architecture of an information system for public relations via a mobile application using in-depth user experience for the proactive perception of information. Characteristics of questions are divided into five levels with assessment and interpretation criteria as follows:

Table 1. Mean score range and interpretation of results

\begin{tabular}{ll}
\hline Average score range & Meaning of interpretation \\
\hline $4.50-5.00$ & The suitability is at the highest level. \\
$3.50-4.49$ & The suitability is at a high level. \\
$2.50-3.49$ & The suitability is at a moderate level. \\
$1.50-2.49$ & The suitability is at a low level. \\
$1.00-1.49$ & The suitability is at the lowest level. \\
\hline
\end{tabular}

\section{Research Results}

The results of design and development of the architecture of an information system for public relations via a mobile application using in-depth user experience for the proactive perception of information. The researcher has summarized the results following the above four objectives. The results can be summarized as follows:

\subsection{Results of Analysis and Synthesis of the Architecture of an Information System for Public Relations via a Mobile Application Using in-depth User Experience for the Proactive Perception of Information}

The results of the study of theories, articles, and related researches defines a conceptual framework for the architecture of an information system for public relations via a mobile application using in-depth user experience for the proactive perception of information. The results of analysis and synthesis were obtained. The details as shown in Figure 1.

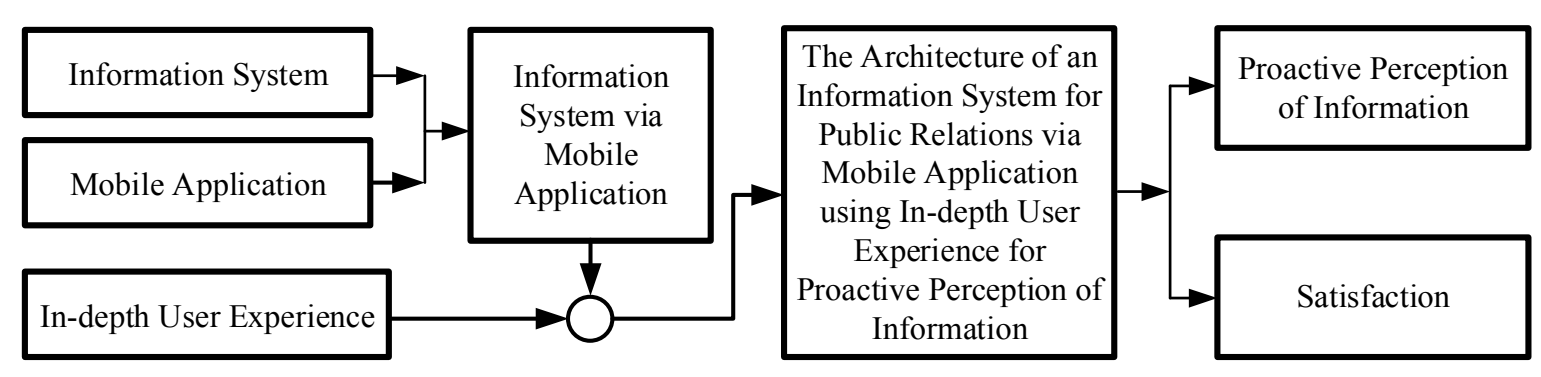

Figure 1. Conceptual framework of the architecture of an information system for public relations via a mobile application using in-depth user experience for the proactive perception of information 
4.2 Results of Designing the Architecture of an Information System for Public Relations via a Mobile Application Using in-depth User Experience for the Proactive Perception of Information Can Be Summarized as Follows

4.2.1 Design of Use Case Diagrams of the Architecture of an Information System for Public Relations via a Mobile Application Using in-depth User Experience for the Proactive Perception of Information, as Shown in Figure 2

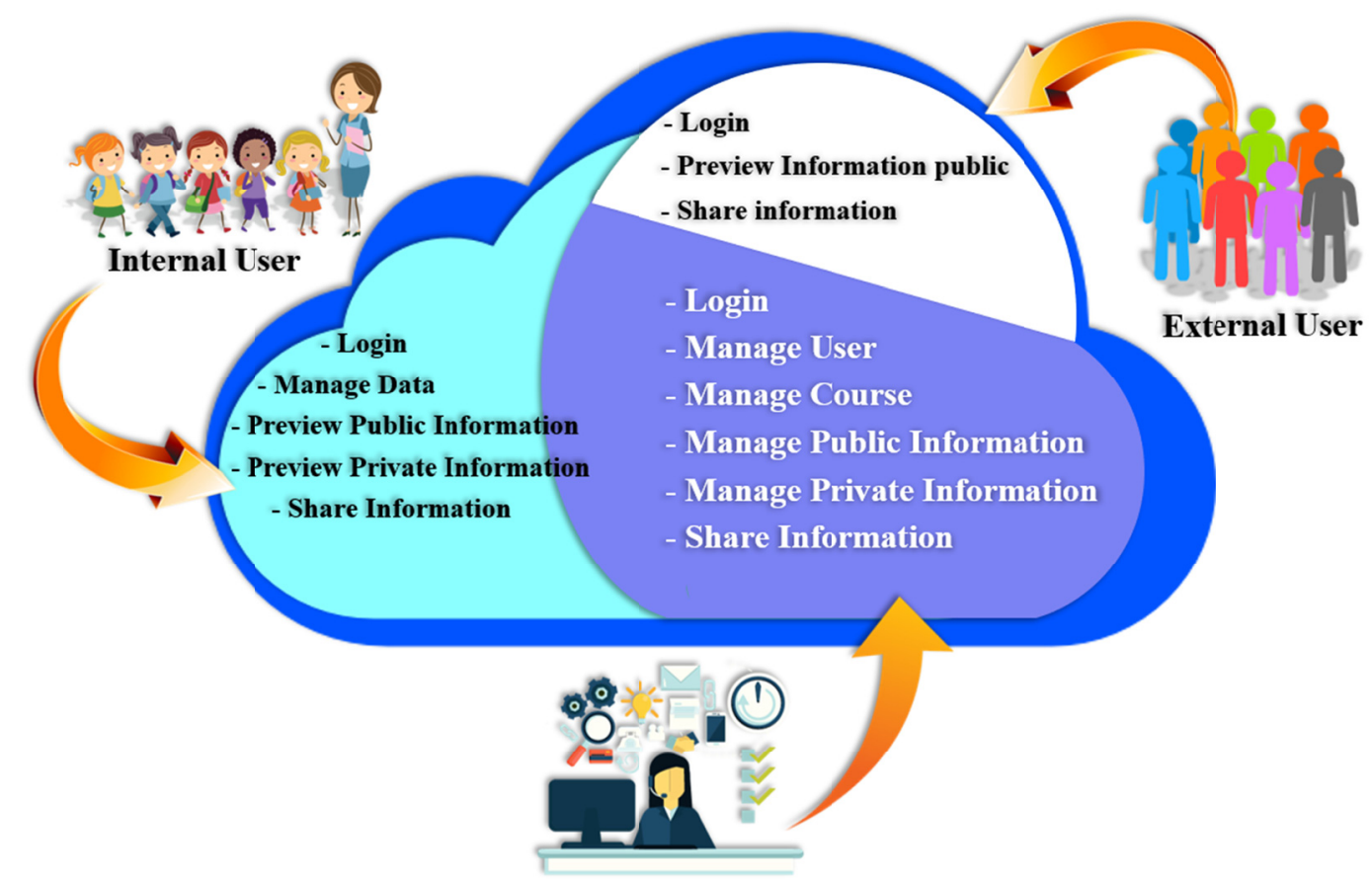

Administrator

Figure 2. The use case diagrams of the architecture of an information system for public relations via a mobile application using in-depth user experience for the proactive perception of information

Figure 2 shows the use case diagrams of the architecture of an information system for public relations via a mobile application using in-depth user experience for the proactive perception of information. The researcher has analyzed and synthesized the system users' needs. The study found that stakeholders with developed information systems for public relations through mobile applications consist of 3 groups: 1) System administrators can login to the system, manage information, manage courses, manage public information, manage internal data, and share information 2) Internal users include students, staffs and teachers who are personnel within the college, can login to the system, manage personal data, preview public information, preview internal information, and share information 3) external users is a third party unrelated to the college, can login to the system, preview public information, and share information, etc. 
4.2.2 Design a Context Diagram of the Architecture of an Information System for Public Relations via a Mobile Application Using in-depth User Experience for the Proactive Perception of Information as Shown in Figure 3

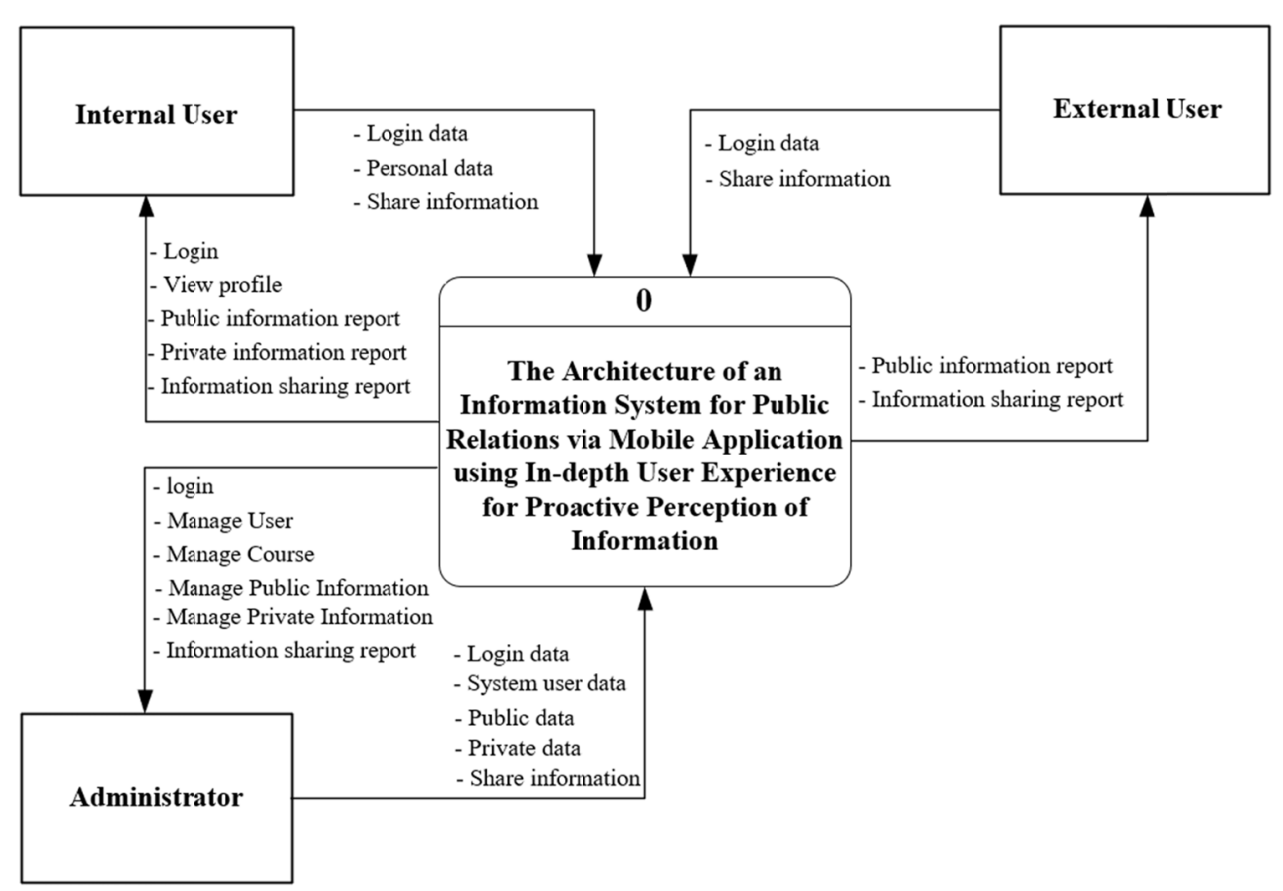

Figure 3. A context diagram of the architecture of an information system for public relations via a mobile application using in-depth user experience for the proactive perception of information

Figure 3 A context diagram of the architecture of an information system for public relations via a mobile application using in-depth user experience for the proactive perception of information shows the relationship of workflow in the system. Including the person involved in the system, to clarify the design of the system. 
4.2.3 Design the Swim Lane Diagrams of the Architecture of an Information System for Public Relations via a Mobile Application Using in-depth User Experience for the Proactive Perception of Information as Shown in Figure 4.

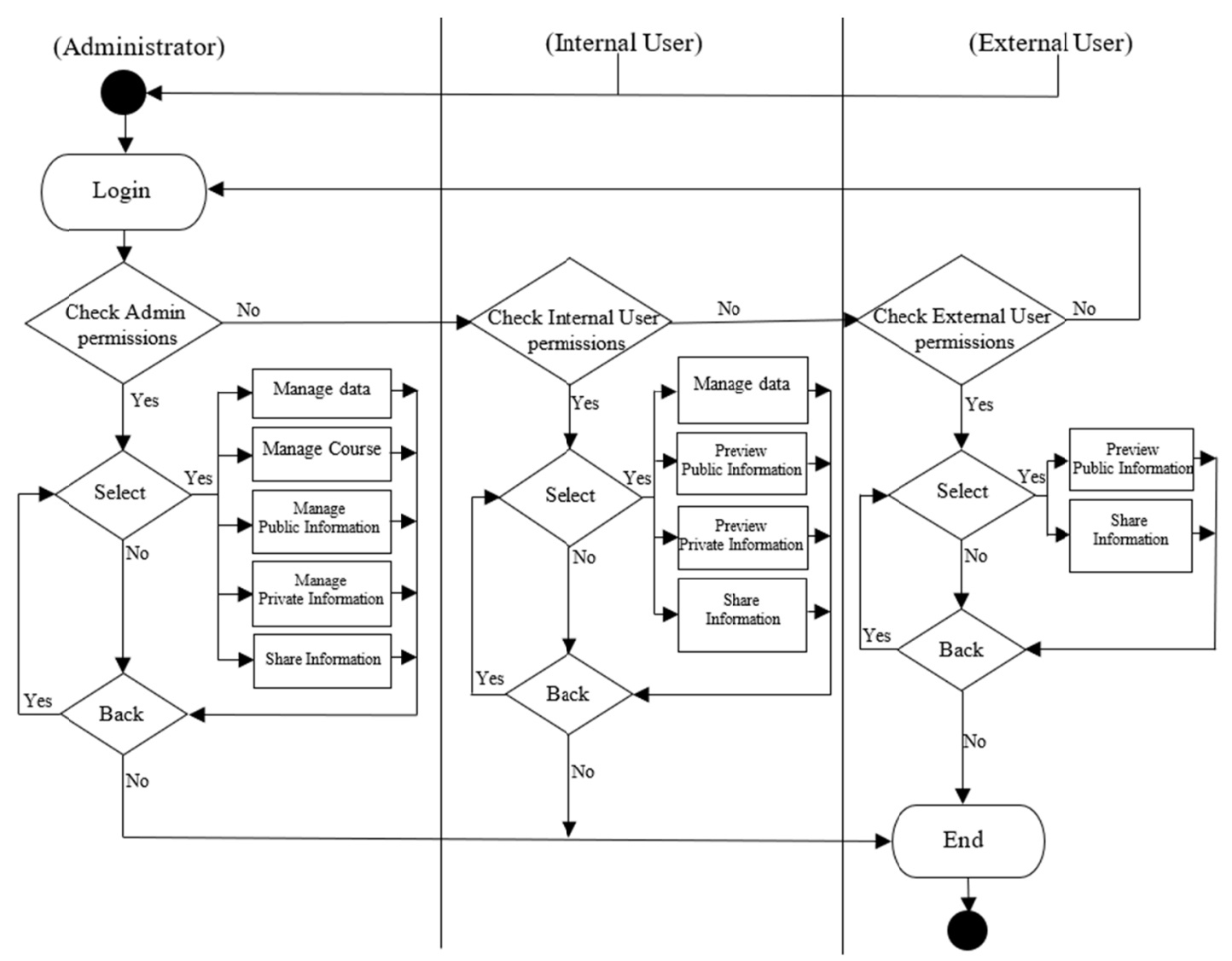

Figure 4. The swim lane diagrams of the architecture of an information system for public relations via a mobile application using in-depth user experience for the proactive perception of information

Figure 4 shows the swim lane diagrams of the architecture of an information system for public relations via a mobile application using in-depth user experience for the proactive perception of information by dividing the work into three groups of users, consisting of the following. (1) Administrators, when entering the list, the options will appear administrator can select the desired item, such as the data management menu, course management menu, public information management menu, internal data management menu, information sharing menu. (2) Internal users, when entering the list, the options will appear internal users can select the desired item, such as managing personal data menu, preview public information menu, preview internal information menu, information sharing menu. (3) External users, when entering the list, the options will appear internal users can select the desired item, such as preview public information menu, information sharing menu, etc.

4.3 Results of the Architecture of an Information System for Public Relations via a Mobile Application Using in-depth User Experience for the Proactive Perception of Information

The concept of designing and developing the architecture of an information system for public relations via a mobile application using in-depth user experience for the proactive perception of information. This information system works through a mobile application where users can access information quickly through smartphones and tablets, as shown in Figure 5. 


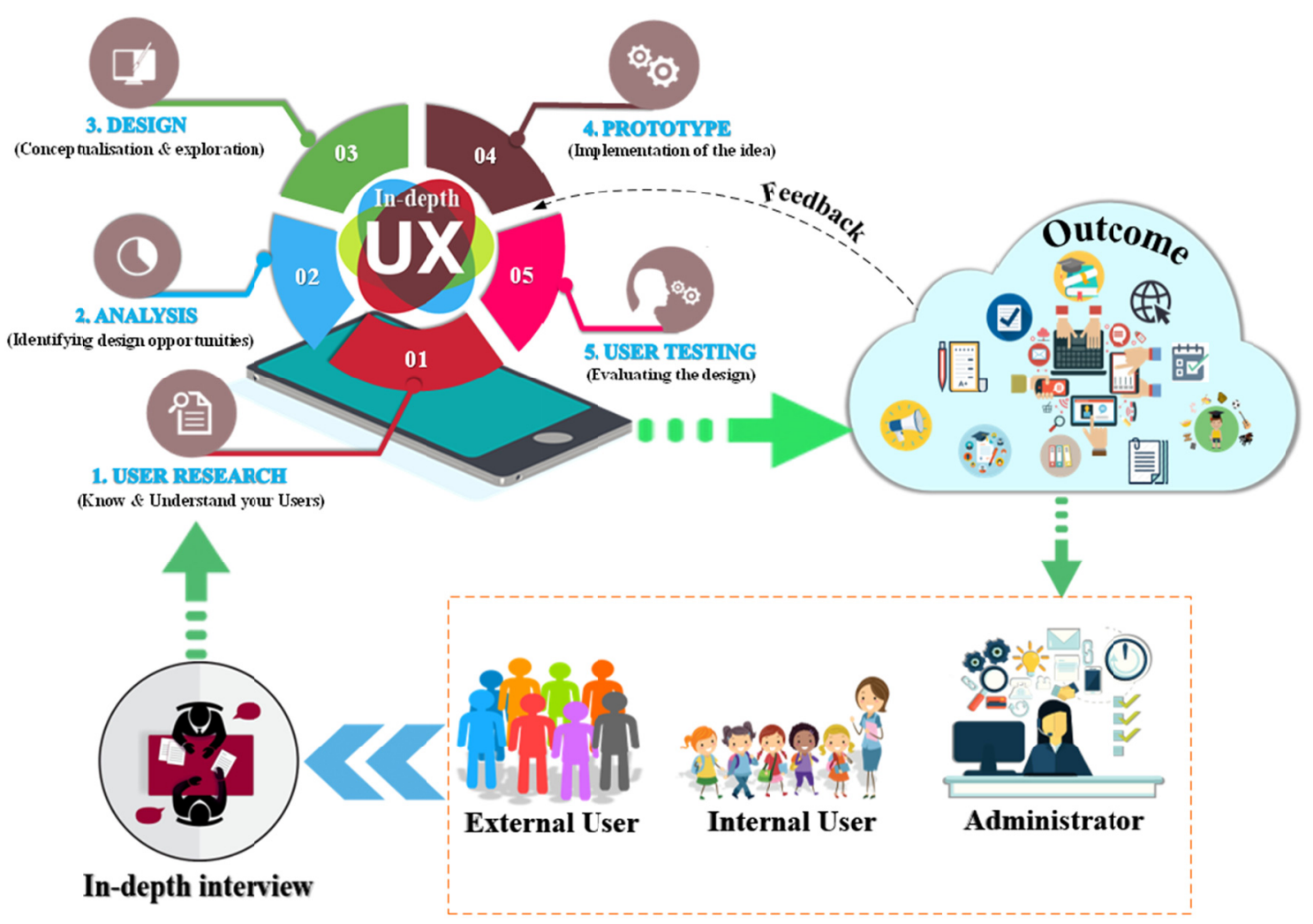

Figure 5. The architecture of an information system for public relations via a mobile application using in-depth user experience for the proactive perception of information

Figure 5 shows the architecture of an information system for public relations via a mobile application using in-depth user experience for the proactive perception of information. This information system works through a mobile application. There are three main components as follows:

1) Stakeholder represents a person related to the development of the information system, consisting of 3 groups of system users as follows. (1) Administrators can manage data of the internal and external person, manage courses, manage public information, and manage information in the developed information system. (2) Internal users are students, staff and teachers who are personnel of the college, can manage personal data, preview public information, and preview information in the developed information system. (3) External users are not related to the college but want to achieve the college's information, can login to preview public information.

2) In-depth user experience process consists of 5steps as follows. 1) Study of the problems and user behaviour (user research). In this step, the researcher uses in-depth interviews to learn about the user group by enquiry the problems and background of the legacy system in detail. To solve problems to meet the core needs of users by studying the experience in using technology similar to the developed information system. Then take the compiled data to analyze the problems further. 2) Analysis, use information obtained from the study of problems and user behaviour to analyze and compile to see the importance of each problem for a plan to determine the needs to meet the core needs. Besides, solve the problems according to the objectives to use as a guideline for further design. 3) Design, after analyzing and compiling the data. This step is to build a prototype of the developing information system. The contents in the system are organized and linked in a hierarchical structure by arranging contents that focus on user actions and categorizing them into various categories. To demonstrate the work of the developed system. 4) Prototype is the process of developing a prototype derived from the concept of analysis and design in step 2 and step 3 to obtain a systematic prototype. The developed information can use appropriately in the future. 5) User testing is the process of bringing the prototype to be evaluated with the users of the developed information system to get feedback for improvement or fixed the system to make it more efficient.

3) Outcome is a product derived from the working process of an information system developed from the 5-steps process of in-depth user experience (UX Process), such as course information, announcements, score data, activity information, college information, and contact information, etc. The information mentioned above are all 
proactive information obtained from working through the process of developed information systems.

4) Feedback consist of expert opinions, proactive perception of information, and satisfaction. This feedback will conduct to improve or fix the system for better performance.

4.4 Results of Assessing the Suitability of the Architecture of an Information System for Public Relations via a Mobile Application Using in-depth User Experience for the Proactive Perception of Information

1) Results of the assessment of the suitability of the architecture of an information system for public relations via a mobile application using in-depth user experience for the proactive perception of information. (Integrated components issue) as shown in Table 2.

Table 2. Results of the assessment of the suitability of the architecture of an information system for public relations via a mobile application using in-depth user experience for the proactive perception of information (integrated components issue)

\begin{tabular}{|c|c|c|c|}
\hline Assessment items & Mean & S.D. & Interpret results \\
\hline 1. The architecture of the developed system corresponds to the research objectives. & 4.60 & 0.50 & Highest \\
\hline 2. Architectural components. & 4.41 & 0.71 & High \\
\hline 3. The hierarchy of the designed architecture components is evident and successive. & 4.50 & 0.61 & Highest \\
\hline 4. Each component is related to the other. & 4.35 & 0.75 & High \\
\hline $\begin{array}{l}\text { 5. The arrangement of components in the system architecture was suitability and easy to } \\
\text { understand. }\end{array}$ & 4.40 & 0.60 & High \\
\hline 6. The overall components of system architecture are perfect and covering the needs. & 4.35 & 0.75 & High \\
\hline Overall (integrated components issue) & 4.43 & 0.67 & High \\
\hline
\end{tabular}

From Table 2, it is found that the architecture of an information system for public relations via a mobile application using in-depth user experience for the proactive perception of information, in the integrated components issue that developed, appropriateness is high (Mean=4.43, S.D. $=0.67$ ). Concluded that the developed architecture of an information system for public relations via a mobile application can use as a guideline for the development of the architecture of an information system for public relations via a mobile application using in-depth user experience for the proactive perception of information.

2) Results of the assessment of the suitability of the architecture of an information system for public relations via a mobile application using in-depth user experience for the proactive perception of information (individual component issue) is shown in Table 3.

Table 3. Results of the assessment of the suitability of the architecture of an information system for public relations via a mobile application using in-depth user experience for the proactive perception of information (individual component issue)

\begin{tabular}{|c|c|c|c|c|}
\hline \multicolumn{2}{|l|}{ Assessment items } & \multirow[t]{2}{*}{ Mean } & \multirow[t]{2}{*}{ S.D. } & \multirow[t]{2}{*}{ Interpret results } \\
\hline Main component & Sub-component & & & \\
\hline \multirow[t]{3}{*}{ 1. Stakeholders } & 1.1 Administrator & 4.50 & 0.69 & Highest \\
\hline & 1.2 Internal users & 4.50 & 0.61 & Highest \\
\hline & 1.3 External users & 4.40 & 0.75 & High \\
\hline Overall & & 4.47 & 0.68 & High \\
\hline 2. In-depth user experience & 2.1 Study of problems and user behaviour & 4.40 & 0.82 & High \\
\hline \multirow[t]{5}{*}{ process } & 2.2 Analyze the problem & 4.30 & 0.80 & High \\
\hline & 2.3 Prototype design & 4.40 & 0.82 & High \\
\hline & 2.4 Build a prototype & 4.40 & 0.82 & High \\
\hline & 2.5 Prototype testing & 4.60 & 0.75 & Highest \\
\hline & Overall & 4.42 & 0.79 & High \\
\hline \multirow[t]{3}{*}{ 3. Outcome } & 3.1 Proactive information & 4.30 & 0.66 & High \\
\hline & 3.2 Satisfaction & 4.50 & 0.61 & Highest \\
\hline & Overall & 4.40 & 0.63 & High \\
\hline \multirow[t]{4}{*}{ 4. Feedback information } & 4.1 Experts' opinion & 4.20 & 1.06 & High \\
\hline & 4.2 Proactive perception of information & 4.15 & 0.99 & High \\
\hline & 4.3 Satisfaction & 4.20 & 0.95 & High \\
\hline & Overall & 4.18 & 0.98 & High \\
\hline \multicolumn{2}{|c|}{ Overall assessment results in individual component issue } & 4.37 & 0.80 & High \\
\hline
\end{tabular}


From Table 3, it is found that the architecture of an information system for public relations via a mobile application using in-depth user experience for the proactive perception of information (individual component issue), experts have commented that the suitability of developed system architecture is highly appropriated for all components. Including stakeholder component (Mean=4.47, S.D=0.68), In-depth user experience process component (Mean=4.42, S.D. $=0.79$ ), outcome component (Mean=4.40, S.D. $=0.63$ ) and feedback data component (Mean=4.18, S.D. $=0.98$ ). The result of an overall assessment of developed system architecture (individual component issue) is highly appropriated (Mean=4.37, S.D.=0.80). Concluded that the developed architecture of an information system for public relations via a mobile application can use as a guideline for the development of the architecture of an information system for public relations via a mobile application using in-depth user experience for the proactive perception of information.

3) Results of assessing the suitability of the architecture of an information system for public relations via a mobile application using in-depth user experience for the proactive perception of information (usage issue) as shown in Table 4.

Table 4. Results of assessing the suitability of the architecture of an information system for public relations via a mobile application using in-depth user experience for the proactive perception of information (usage issue)

\begin{tabular}{llll}
\hline Assessment items & Mean & S.D. & Interpret results \\
\hline $\begin{array}{l}\text { 1. To what extent does the developed architecture of an information system respond to the } \\
\text { proactive perception of information? }\end{array}$ & 4.30 & 0.80 & High \\
$\begin{array}{l}\text { 2. To what extent does the developed architecture of an information system has an in-depth } \\
\text { user experience (UX Process) that can promote the proactive perception of information? }\end{array}$ & 4.10 & 0.72 & High \\
$\begin{array}{l}\text { 3. To what extent does the developed architecture of an information system feasible to } \\
\text { implement? }\end{array}$ & 4.10 & 0.72 & High \\
Overall (usage issue) & 4.17 & 0.74 & High \\
\hline
\end{tabular}

From Table 4, it is found that the architecture of an information system for public relations via a mobile application using in-depth user experience for the proactive perception of information, it is suitable for usage issue in overall at highly appropriated (Mean=4.17, S.D. $=0.74$ ). Concluded that the experts accepted the idea of developing system architecture developed by the researcher. The concept can apply to develop an information system for public relations via a mobile application using in-depth user experience for the proactive perception of information for actual usage further.

\section{Summarize and Discussion of the Results}

This research is a study of the design and development of the architecture of an information system for public relations via a mobile application using in-depth user experience for the proactive perception of information. It is designed and developed from the study, analyze and synthesize the components of information systems and mobile applications. Conducted by studying and analyzing the principles, the concept of the components by applying the coherent concept to define the components of the information system for public relations via a mobile application using in-depth user experience for the proactive perception of information. The researcher has studied the research papers by applying consistent principles and concepts to define the components. The results can be summarized and discussed as follows:

\subsection{Conclusions}

Development of the architecture of an information system for public relations via a mobile application using in-depth user experience for the proactive perception of information revealed that there are four components of the system architecture as follows. 1) Components of stakeholders include administrator, internal users, and external users. 2) The workflow of the in-depth user experience consists of studying problems and user behaviour, analyze problems, design prototypes, build prototypes, and prototypes testing. 3) Outcome consists of proactive information and satisfaction. 4) Feedback data consists of experts' opinion, the proactive perception of information, and satisfaction.

Results of assessing the suitability of the development of the architecture of an information system for public relations via a mobile application using in-depth user experience for the proactive perception of information by 20 experts in the development of information systems from various institutions in higher education. The assessment results found that 1) the suitability of the developed system architecture (Integrated components) is highly appropriated (Mean=4.43, S.D.=0.67) 2) the suitability of the developed system architecture (Individual 
component) is highly appropriated (Mean $=4.37$, S.D. $=0.80)$ 3) The results of assessing the suitability in the implementation of the developed system architecture is highly appropriated (Mean=4.17, S.D. $=0.74$ ), respectively.

\subsection{Discussion of the Results}

The architecture of an information system for public relations via a mobile application using in-depth user experience for the proactive perception of information, there are issues for discussions of the results, related documents and researches as follows.

Results of the development of the architecture of an information system for public relations via a mobile application using in-depth user experience for the proactive perception of information found that the concept of the architecture of an information system for public relations via a mobile application using in-depth user experience for the proactive perception of information is highly appropriated from the experts' opinion. Due to the development of the architecture of an information system for public relations via a mobile application using in-depth user experience for the proactive perception of information has been developed systematically, by studying relevant research documents to be used as guidelines for development, and a guideline for developing the architecture of an information system via a mobile application. Using information and communication technology systems to support the management of efficiency in the management of information and public relations to be convenient, fast, and economical. Besides, as a guideline for the development of an application, distributing information, public relations, and collecting data to achieve speedy communication, effective information integrity and reliability. This is consistent with the study of Chatwattana (2021). He said that bringing tools to promote learning in the digital era using new ideas and innovations can respond and support the existing world situation and enable students to learn anytime, anywhere with unlimited access to education through digital technology. It shows how to make the most of the current technology. This educational approach may lead to the creation of learning in the digital university society in the future.

Results of assessing the suitability of the development of the architecture of an information system for public relations via a mobile application using in-depth user experience for the proactive perception of information, in overall as a highly appropriated (Mean=4.75, S.D. $=0.43$ ). In line with Karapakdee and Chatwattana (2016) study, learning via portable mobile devices can assist facilitate. Besides, encourage students to learn and able to receive information anytime, anywhere proactively. In the same direction, a study of Davidovitch, Belichenko and Kravchenko (2017) stated that, use of information resources to manage digital learning systems enables distance learning of students and teachers on campus. It is very convenient during rush hour, especially when students and teachers are working abroad. In addition, it can assist students and teachers gain the necessary knowledge whenever they need it. The mentioned above consistent with a study by Ko and Lim (2021) that designed a mobile application to aid learning; quality spoke English pronunciation for high school, which has content to promote access to English speaking skills. It also allows students to improve their English-speaking skills using a mobile application on their own.

\section{References}

Chatwattana, P. (2021). A MOOC system with self-directed learning in a digital university. Global Journal of Engineering Education, 23(2), 134-142.

Chatwattana, P., \& Piriyasurawong, P. (2015). Web Creative Intelligent Tutoring Model to Develop Creative Problem Solving Skill and Learning Achievement. FEU Academic Review, 8(2), 87-101.

Chiemwichitra, S. M. C. (2015). Information Exporsure and Factor of Communication that Affect Brand Equity: The Case Study on The Hub Rangsit Pathum Thani Province. Bangkok University.

Davidovitch, N., Belichenko, M., \& Kravchenko, Y. (2017). Information Resources Usage in Project Management Digital Learning System. Journal of Education and Learning, )62(, 146-154. https://doi.org/10.5539/jel.v6n2p146

Fichten, C. S., Nguyen, M. N., King, L., Barile, M., Havel, A., Mimouni, Z., ... Jennison, A. (2013). Information and Communication Technology Profiles of College Students with Learning Disabilities and Adequate and Very Poor Readers. Journal of Education and Learning, 2(1), 176-188. https://doi.org/10.5539/jel.v2n1p176

Jawdat, A., Obeidat, Q., \& Aljanaby, A. (2011). On The Design of User Experience Based Persuasive Systems. Computer and Information Science, 4(4), 90-99. https://doi.org/10.5539/cis.v4n4p90

Jirasatjanukul, K., Nilsook, P., \& Wannapiroon, P. (2019). Intelligent Human Resource Management Using 
Latent Semantic Analysis with the Internet of Things. International Journal of Computer Theory and Engineering, 11(2), 23-26. https://doi.org/10.7763/IJCTE.2019.V11.1235

Karapakdee, J., \& Chatwattana, P. (2016). Development of Smart Navigation by using Augmented Major Field Reality Location-based Services via Mobile Device. Information and Communication Technology for Education, King Mongkut's University of Technology North Bangkok.

Ko, E. G., \& Lim, K. Y. (2021). Promoting English Learning in Secondary Schools: Design-Based Research to Develop a Mobile Application for Collaborative Learning .The Asia-Pacific Education Researcher, 1-13. https://doi.org/10.1007/s40299-021-00562- 0

Mongkol, C. (2017). Government officers's Uses and Gratification of LINE Messenger Application for Work. Arts (Strategic Communications), May 2018, Graduate School, Bangkok University.

Ngewtong, T. (2017). Application Of UX Research and Design-Based Research to Develop a Prototype of Teachers' Collaborative Research Learning Enhancement. Chulalongkorn University.

Phiraphon, T. (2018). User Experience Design of Artificial Intelligent Technology. Journal of Science and Technology, 12(1), 39-45.

Rita S. Y. B. (1999). Collecting data by in-depth interviewing. Retrieved July 7, 2021, from http://www.leeds.ac.uk/educol/documents/000001172.htm

Rodsoodthi, S. (2018). Participation Technique for "User Experience" in Library Service 4.0. The Journal of Library and Information Science Srinakharinwirot University, 11(1), 210-219.

Saenkham, T., Jeewattana, S., \& Pimklat, N. (2019). The Development of Information System for Operational Planning of Administrators in Bandan Subdistrict Municipality, Bandan District, Buriram Province. Journal of Information Technology Management and Innovation, 6(1), 79-88.

Satmunee, J., \& Boriruk, S. (2019). The Supporting Development of the Public Relations Management System for the Educational Institution. Journal of Information Technology Management and Innovation, 6(1), $61-68$.

Sombut, P., \& Manon, W. (2016). Development Guideline for Mobile Application Thai Mobile for Customers of Thai Airways International Public Company Limited. MBA-KKU Journal, 9(1), 100-116.

Tivawong, N. (2012). A Web-Based Information System for Performance Evaluation Case Study: Royal Thai Armed Forces Headquarter. Department of Computer and Communication Technology Faculty of Engineering, Dhurakij Pundit University.

Waraporn, D. (2019). Social Media for Teaching and Learning in the 21 st Century. Journal of Liberal Arts, 7(2), $143-159$.

Yilmaz, O. (2016). E-Learning: Students Input for Using Mobile Devices in Science Instructional Settings. Journal of Education and Learning, 5, 182. https://doi.org/10.5539/jel.v5n3p182

\section{Copyrights}

Copyright for this article is retained by the author, with first publication rights granted to the journal.

This is an open-access article distributed under the terms and conditions of the Creative Commons Attribution license (http://creativecommons.org/licenses/by/4.0/). 